\title{
Research on Material Irradiation in HANARO
}

\author{
Man-Soon Cho*, Kee-Nam Choo, Seoung-Woo Yang, Sang-Jun Park \\ Department of Research Reactor Utilization, Korea Atomic Energy Research Institute, Daejeon, South Korea \\ Email: ${ }^{*}$ mscho2@kaeri.re.kr
}

Received 12 June 2014

\begin{abstract}
HANARO (High-Flux Advanced Neutron Application Reactor) is a 30MWth multi-purpose research reactor generating a very high neutron flux for scientific and technical applications. Since its initial criticality in Feb. 1995, it has worked as a national neutron source for neutron beam research, RI production and related research, material and fuel irradiation research, and neutron transmutation doping. The installation of a cold neutron source and related beam instrument makes HANARO serve as a regional source for beam research as well. As Korea is developing nuclear power systems and fuels, irradiation research is a main utilization subject in HANARO, and irradiation facilities have been actively utilized for various nuclear fuel and material irradiation tests requested by users from research institutes, universities, and industries. Most of the irradiation tests were related to the $R \& D$ relevant to the ageing management and safety evaluation of the present nuclear power reactors. Korea is conducting $R \& D$ programs relevant to new nuclear systems including a research reactor, System-integrated Modular Advanced Reactor (SMART), and future nuclear systems such as a very high temperature reactor system (VHTR) and sodium cooled fast reactor system (SFR). To effectively support the R\&D for new nuclear systems, advanced irradiation technologies such as high-temperature irradiation, instrumentation, and long-term irradiation are being developed. In addition, research on the irradiation characteristics of super-conductor materials and new chemical materials is being conducted as a part of fundamental research.
\end{abstract}

\section{Keywords}

HANARO, Neutron, Flux, Irradiation, SMART, VHTR, SFR

\section{Introduction}

HANARO (High-flux Advanced Neutron Application Reactor) was designed to obtain a high density neutron flux $\left(5 \times 10^{14} \mathrm{n} / \mathrm{cm}^{2} \mathrm{sec}\right)$ with a relatively low thermal output (30 MW) to be utilized in various studies such as fuel and material tests, radioisotope production, neutron activation analysis, neutron beam utilization, neutron transmutation doping, etc. It was on Feb. 8, 1995 that HANARO, designed and constructed by Korean engineers, achieved first criticality. HANARO is a typical multipurpose research reactor using all three kinds of neutrons. Though it cannot be equivalent to a reactor using only one or two kinds of neutrons, HANARO provides most

${ }^{*}$ Corresponding author. 
areas of its utilization capabilities for global competition

In HANARO, the inner core has 28 fuel sites and 3 test sites. The 3 test sites of CT, IR1 and IR2, are hexagonal in shape and are used for irradiation of the capsules, FTL (Fuel Test Loop), and RI (Radioisotope) production. The outer core consists of 4 fuel sites and 4 test sites (OR1 to 8), which are embedded in the reflector tank. In addition, there are several vertical test holes such as LH (Large Hole), HTS (Hydraulic Transfer System), NTD (Neutron Transmutation Doping) and IP (Irradiation Position) in the reflector region for the irradiation tests, RI production and NTD, as shown in Figure 1.

\section{Irradiation Capsules in HANARO}

Irradiation tests of the materials at HANARO have been performed usually at temperatures of $250^{\circ} \mathrm{C}-400^{\circ} \mathrm{C}$, at which the RPV materials of PWR reactors are being operated up to the present. They have been performed using a standard capsule. As the reactors planned in the Gen-IV program will be operated at high temperature and under high neutron flux, the requirements for the irradiation of materials at high temperature and flux are recently being gradually increased. The operating temperatures of the VHTR and SFR are expected to be $1000^{\circ} \mathrm{C}$ and $550^{\circ} \mathrm{C}$, respectively [1], which are much higher than the irradiation temperatures of material capsules tested at HANARO up to recently. On the other hand, KAERI is participating in the development of new research reactors, i.e., the Ki-Jang of Korea and the JRTR of Jordan. The materials used for the reflector of research reactors are graphite, beryllium, and Zircaloy. They are operating at low temperature of less than $100^{\circ} \mathrm{C}$, and thus irradiation data at low temperature are necessary. The capsules in HANARO have been developed according to the various temperature requirements. They are classified as a standard capsule, a high-temperature capsule, and a low-temperature capsule, which are used respectively for irradiation at temperatures of $200^{\circ} \mathrm{C}-500^{\circ} \mathrm{C}$, lower than $100^{\circ} \mathrm{C}$, and higher than $700^{\circ} \mathrm{C}$. In addition, the various irradiation facilities such as a rabbit, small non- instrumented capsule, loop, and target for RI production are used at HANARO. Analyses for the reactivity effect, neutron flux, and gamma heating necessary for capsule design are performed mainly by the common MCNP code. The irradiation temperature is analyzed using the GENGTC and ANSYS codes.

\subsection{Standard Capsule}

The standard capsules are mostly used for irradiation at temperatures of $250^{\circ} \mathrm{C}-400^{\circ} \mathrm{C}$. The development of the standard material capsule and the related technology started in 1995, and it was first irradiated in HANARO in 1998. Now, it has an important role in the integrity evaluation of the reactor core materials and the development of new materials through the irradiation tests of specimens such as RPV, reactor core, pressure tube, fuel cladding of PWR, and high-technology materials. The standard capsule, which is usually called an instrumented material capsule, is shown in Figure 2. It is cylindrical in shape, and its main-body is about $60 \mathrm{~mm}$ in diameter and $870 \mathrm{~mm}$ in length. It consists of three parts connected to each other: a protection tube, a guide tube, and the main body. The main body including the specimens and instruments is a cylindrical shaped stainless steel tube.

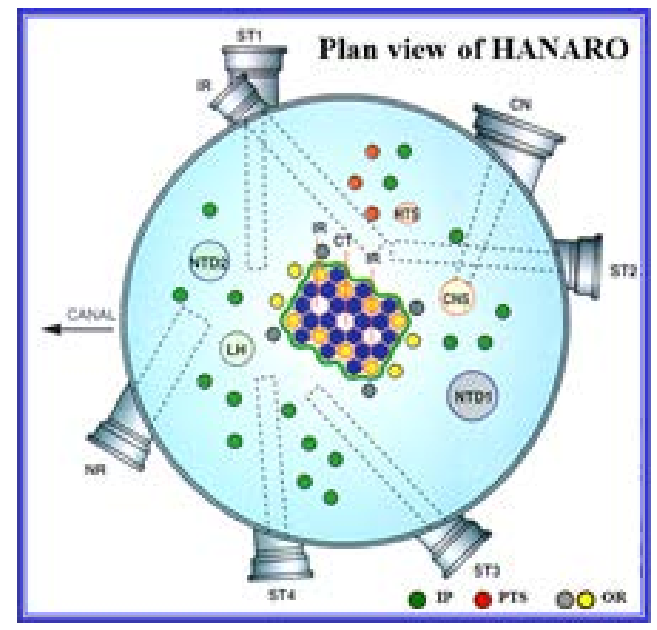

Figure 1. HANARO core. 


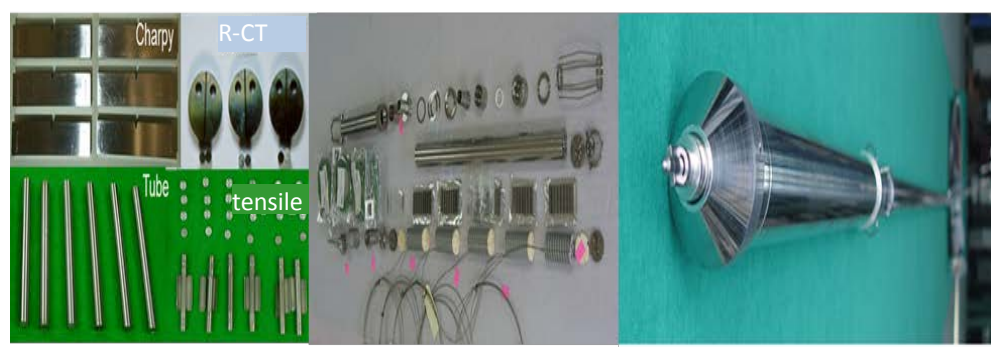

Figure 2. Standard capsule, parts and specimens.

\subsection{Low-Temperature Capsule}

The concept of a low-temperature capsule is direct contact with the coolant to cool the specimen down. The capsule makes the reactor coolant pass through the bottom hole, as shown in Figure 3, which is different with the configuration of a standard capsule filled with He in a sealed atmosphere.

The low-temperature capsule is used for irradiation of the reflector material in a research reactor, such as graphite, beryllium, and zircaloy-4, because the research reactors are usually operating at low temperature $\left(<100^{\circ} \mathrm{C}\right)$. The results will be utilized for an acquisition of the irradiation data necessary for the design of research reactors such as JRTR and Ki-jang.

\subsection{High-Temperature Capsule}

The high-temperature irradiation capsule which will be used for high-temperature irradiation of up to $1000^{\circ} \mathrm{C}$ has been developed as a concept with double thermal media, as shown in Figure 4. Because the Al thermal media used in a standard capsule might melt at high temperature, other materials enduring high temperature such as $\mathrm{Ti}$ or $\mathrm{Zr}$ should be used as the inner thermal media holding specimen. This capsule is being developed to use for irradiation of VHTR material.

\subsection{Others}

In addition, various neutron irradiation facilities such as a rabbit, non-instrumented capsule, target for radioisotope production, and fuel capsules have been developed at HANARO. The rabbit and target were originally designed for NAA and RI production, but they can also be used for irradiation of fuel and material.

Non-instrumented capsules have been used for a test in which the irradiation temperatures are required to be in a large range or for the irradiation of nuclear fuel. It is typically $1 \mathrm{~m}$ in length and $56 \mathrm{~mm}$ in diameter. It was used mainly for the irradiation of DUPIC, Advanced PWR, and CANDU fuels. It is currently being used for the irradiation of concrete material, SPND, and U-moly, VHTR and SFR fuel.

\section{Recent Utilization of Irradiation Capsules}

As the integrity assessment and lifetime extension of NPP are posing a big social problem around the world after Fukushima accident, the irradiation data for structural materials and nuclear fuels for NPP are indispensable and some are urgently required in Korea. Because the future nuclear energy systems are being developed as a method to get the new energy source worldwide and Korea participates in development of SFR and VHTR, the irradiation capabilities are emerging as an important issue at the present time. Recently, the irradiation test for research reactor materials has been finished, and that for RPV materials was performed in HANARO. And the irradiation tests for VHTR and SFR fuel are being carried out as well as fusion reactor materials for development of the future nuclear systems. In addition, the instruments such LVDT and SPND are being developed. The recent irradiation status is described simply as below.

\subsection{High-Dose Irradiation of RPV Steel for Currently Operation PWR}

The continued utilization of nuclear energy systems for worldwide base load electricity offers a number of materials research challenges. One of the major degradation issues for reactor pressure vessel (RPV) steels is embrittlement associated with hardening from radiation induced solute-defect clusters. However, the effects of 

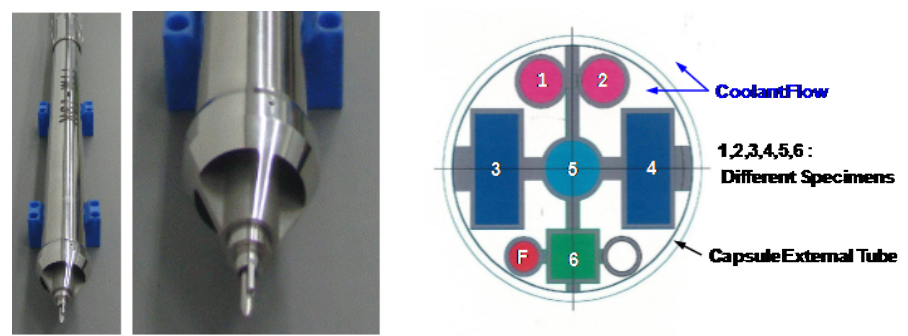

Figure 3. Low-temperature capsule.

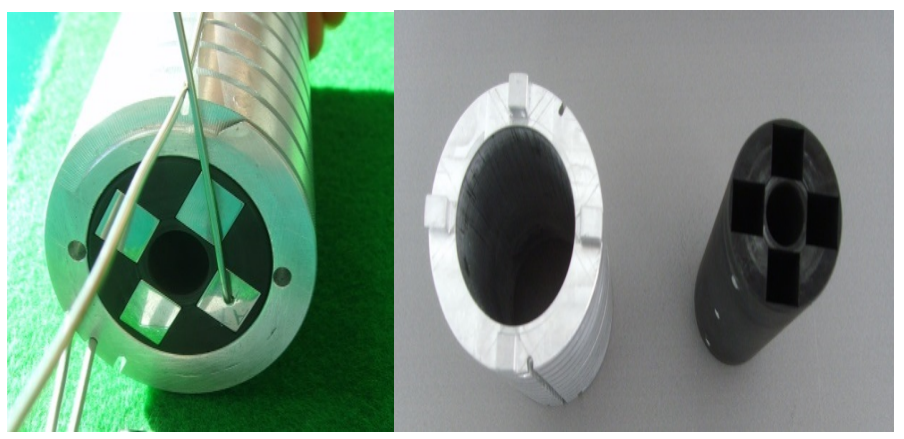

Figure 4. High-temperature capsule.

high-dose, long-term operation lifetimes and irradiation flux on hardening and embrittlement of RPV steel are now well-known worldwide. It is needed to obtain data from domestic RPV steel after high-dose irradiation for te potential extension of reactor operation licensing of nuclear power plants beyond their initial term. The specimens are the archive material of SA 508-Cr.3 RPV steel. 58 specimens for tension, fracture toughness and Charpy impact testing were inserted in the capsule and irradiated at fluence up to $5.51 \times 10^{19}\left(\mathrm{n} / \mathrm{cm}^{2}\right)(\mathrm{E}>1.0$ $\mathrm{MeV}$ ). The irradiation temperature was controlled at $290^{\circ} \mathrm{C} \pm 10^{\circ} \mathrm{C}$. The tension testing was conducted in the range of $25^{\circ} \mathrm{C}-371^{\circ} \mathrm{C}$ with strain rate of $5.6 \times 10^{-4} / \mathrm{s}$, and the result is shown in Figure 5 [2]. The loading rate of the fracture toughness test was $0.15 \mathrm{~mm} / \mathrm{min}$ that corresponds to $1 \mathrm{MPa} \mathrm{m} / \mathrm{s}$. The test results for irradiated RPV steel will be compared with the results for pre-irradiated RPV steel.

\subsection{Irradiation of RR (Research Reactor) Materials}

Recently, Korea has much concern for development and export of RR because it succeeded to export a RR to Jordan and began to construct a new RR in Ki-jang which is located in the southern part. However, the irradiation data for core structural materials such as graphite [3], beryllium and zircaloy-4 are very difficult to find, and so they are being the important issues for design and license of RR. Especially, it is very difficult to obtain the irradiation data at the low temperature below $100^{\circ} \mathrm{C}$, which is operating condition of RR. Accordingly, producing the irradiation data for RR materials by ourselves is required at this time. The irradiation tests were finished in the early of 2014, some of the results were obtained. Figure 6 shows the specimen temperatures during irradiation. The irradiation growth was measured in the hot cell. For Be, the results are almost same with S20F and EHP56. The irradiation growths of $\mathrm{Zr}-4$ are almost same in the rolling and tangential directions. The hardness values increased slightly after irradiation.

\subsection{Irradiation of Reinforced Concrete}

Reinforced concrete (RC) is a composite material in which the concrete's relative low tensile strength and ductility is counteracted by steel bars as reinforcement in tensile regions. It is commonly used as a biological shield and as a load carrying support for a reactor vessel and, if any, changes in the mechanical properties can be particular significant for long-term irradiation. This study aims to investigate the response of a beam member in the RC design for long-term irradiation that RC supporting the reactor vessel may experience [4]. The RC structure close to the reactor vessel was considered as the most critical in estimating that the total fluence for 40 years 


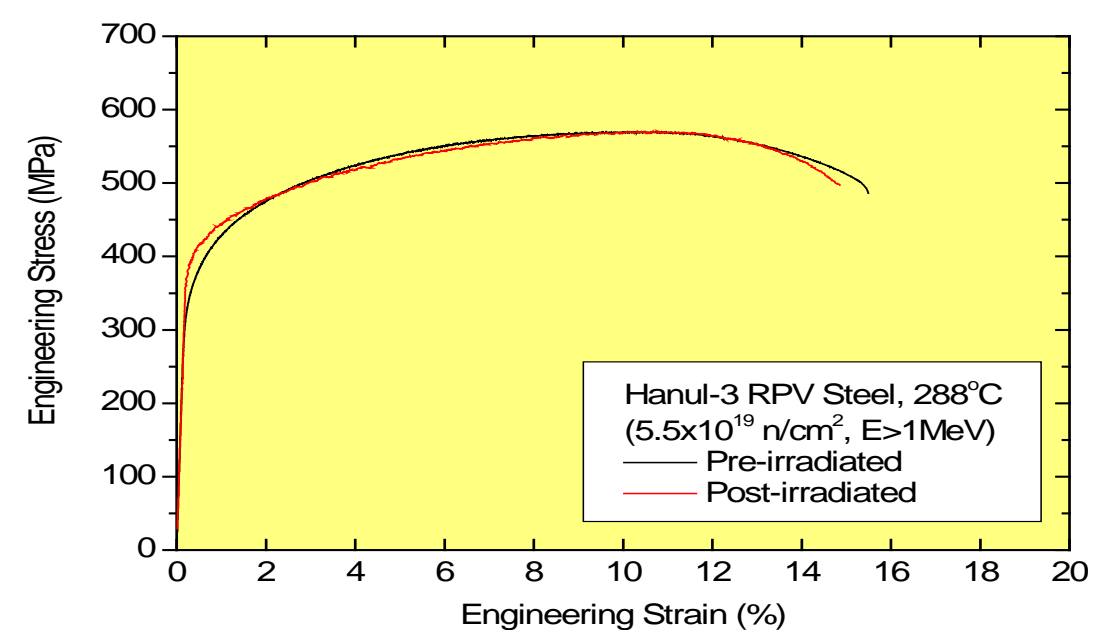

Figure 5. Tensile strength of RPV steel [2].

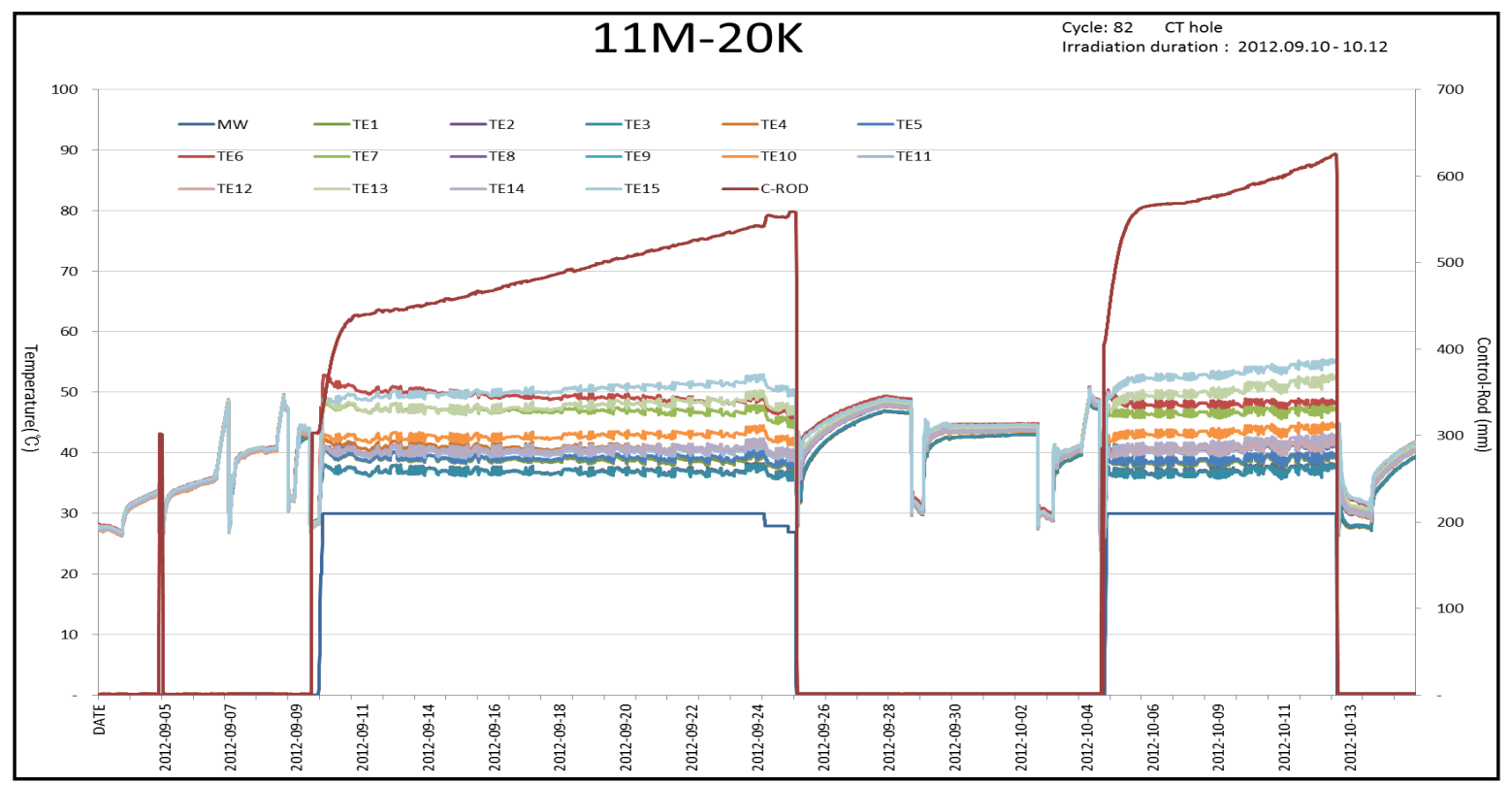

Figure 6. Irradiation of RR materials.

becomes about $10^{14}$ to $10^{18} \mathrm{n} / \mathrm{cm}^{2}$. The moment-curvature response of an RC beam was investigated with the maximum neutron fluence up to $10^{19} \mathrm{n} / \mathrm{cm}^{2}$ and it shows twice the increase in ultimate strength, which is mainly contributed from the increased yield stress of mild steel. The RC beam response became so brittle that it may fail without large deformation as a warning. The same observation can be equally applied to other RC designs such as the column, slab, and foundation. Furthermore, the current investigation will be extended to a structural integrity evaluation of aging NPPs.

\subsection{Irradiation the Mini Plate Type U-7Mo Fuel for Research Reactor}

U-Mo particle dispersion in an aluminum matrix, termed as U-Mo/Al hereafter, has been under development for the use of high power research and test reactors because of its potential for high U-density. Interaction layer growth and occasional porosity formation in the matrix, however, has been hampering its qualification [5]. An excessive interaction layer growth and pore formation in the interaction layers observed in this fuel. Performance of the plate type U-7 wt\% Mo dispersed in an Al-5 wt\% Si alloy matrix, is being investigated through irradiation tests in HANARO at KAERI. These tests will be performed three times as the burn-up rate of $45 \%$, $65 \%$ 
and $85 \%$ respectively. Currently, the 1st mini-plate type of U-Mo fuel is being irradiated for 5 months in HANARO. Post-irradiation metallographic features and swelling etc. will be investigated after irradiation.

\subsection{Irradiation of Coated Particle Fuel}

TRISO (tri-structural isotropic) coated particle fuel has been studied extensively around the world. It consists of a microspheric $\mathrm{UO}_{2}$ fuel kernel surrounded by four coated layers; buffer, $\mathrm{IP}_{\mathrm{y}} \mathrm{C}$ (inner pyrolytic carbon), $\mathrm{SiC}$ and $\mathrm{OP}_{\mathrm{y}} \mathrm{C}$ (outer pyrolytic carbon). Development of fuel is being progressed favorably for use in the VHTR which will be developed in Korea. The first irradiation test of the coated particle fuel has been recently finished. The capsule was loaded in OR5 hole in HANARO core, which has a nominal fast neutron flux of $1.2-1.5 \times 10^{13}$ $\mathrm{n} / \mathrm{cm}^{2} \mathrm{~s}$ and a thermal neutron flux $2.0-2.5 \times 10^{14} \mathrm{n} / \mathrm{cm}^{2} \mathrm{~s}$.

\subsection{Irradiation of Si and SiC etc.}

The basic researches for Si and Sic etc. are proceeding mainly by professors at universities. The microwave losses of single crystalline $\mathrm{Si}$ and $4 \mathrm{H}-\mathrm{SiC}$ are being studied because it is one of the most important physical parameters with regard to the applicability of microwave devices. The loss tangent (tangent $\delta$ ) of $4 \mathrm{H}$-SiC appeared to increase significantly when the specimen was irradiated with thermal neutrons [6]. On the other hand, SiC has attracted interests in radiation research due to the potential to be used in devices operating in high power ranges and high temperatures space application as well as neutron detectors. These applications may involve the integration of semiconductor devices into satellite systems in earth orbit, so as to operate for years in a radiation environment at widely varying temperatures. After neutron irradiation of $\mathrm{SiC}$, a slight positive shift in threshold voltage shift has been observed, which is attributed to charge damages in the SiC layer. In addition, the improvement of critical current of superconducting material is important for the application. It can be achieved by forming the nano-size defect working as a flux pinning center inside superconductor. The nano-size defect can be effectively formed by using neutron irradiation in HANARO. Figure 7 shows change of current density of MgB2 due to irradiation.

\subsection{Statistics for Irradiation Samples and Users}

The national research and development program on nuclear technology in Korea requires the irradiation tests of various materials at HANARO. The main activities of the capsule utilization programs are focused on the in-reactor material tests, safety-related research, and fundamental material research. 11,000 specimens from research institutes, nuclear industry companies, and universities have been irradiated at HANARO for 122,000 hours using capsules and rabbit irradiation systems since 1995. Figure 8 shows the increasing trends of the irradiation specimens and users.

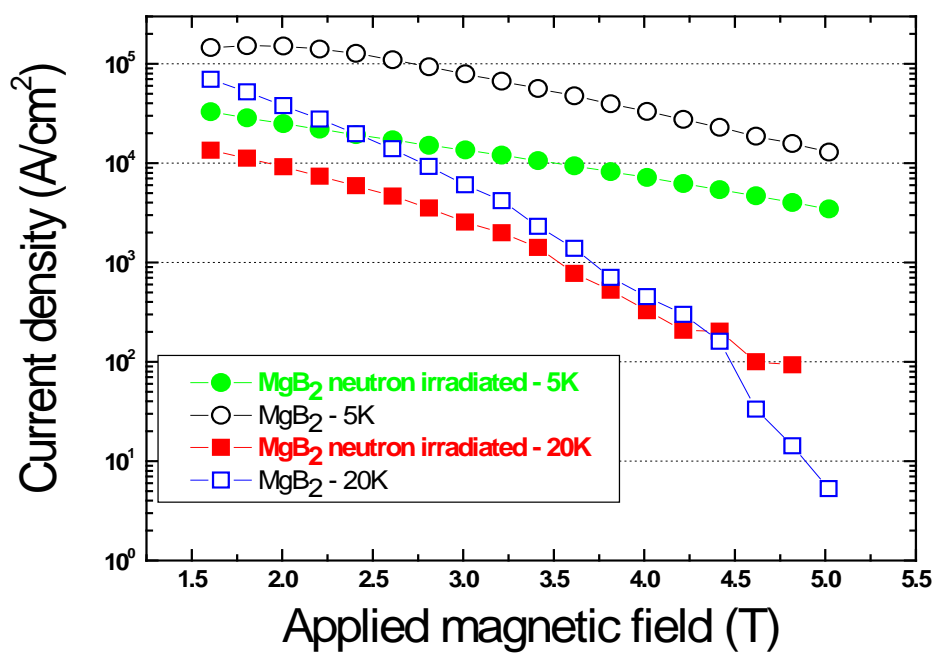

Figure 7. Change of current density. 


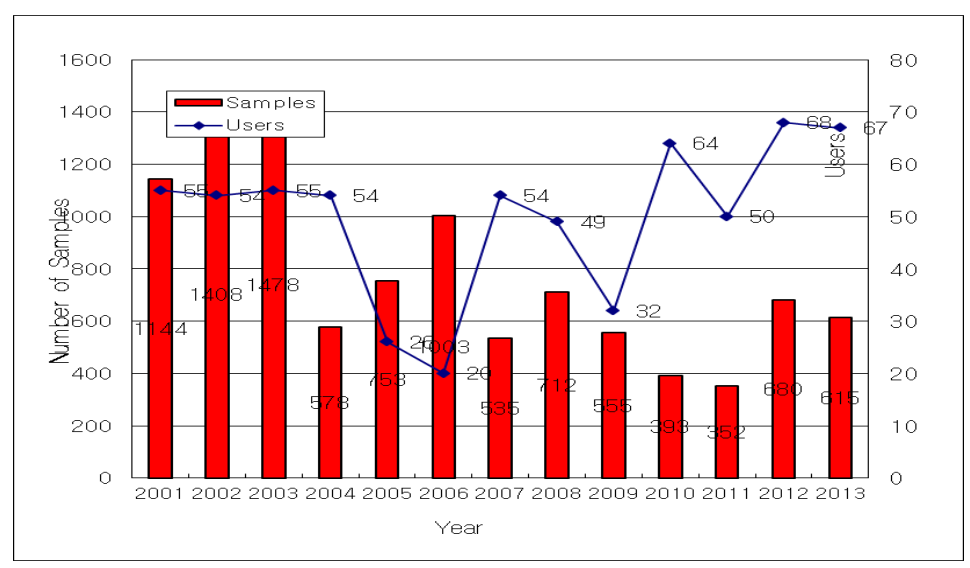

Figure 8. Irradiation samples and users in HANARO.

\section{Conclusion}

Korea is conducting R \& D programs relevant to new nuclear systems including a research reactor, future nuclear systems such as a very high temperature reactor system (VHTR) and sodium cooled fast reactor system (SFR) and fusion reactor system. In addition, research on the irradiation characteristics of super-conductor materials and new chemical materials is being conducted as a part of fundamental research. Irradiation tests in HANARO are mostly related to the R \& D relevant to the ageing management and safety evaluation of the present nuclear power reactors and development of the future nuclear system and production of design data of research reactor. The HANARO irradiation capsule system has been developed and actively utilized for the irradiation testing of fuels and materials. The irradiation tests of materials up to the present have been performed usually at temperatures below $300^{\circ} \mathrm{C}$, at which the RPV of PWR materials is being operated. As the irradiation tests of the materials and fuels for a Gen-IV nuclear system are recently required and the development of new research reactors is ongoing in Korea, the capsules for high- and low-temperature irradiation are being developed at HANARO. The capsules will cover the overall range of temperature from low to high. They will be used for the irradiation of materials and fuel used in a VHTR, SFR, and newly developed research reactors.

\section{Acknowledgements}

This work was supported by the National Research Foundation of Korea (NRF) grant funded by the Korea government (MSIP) (NRF-2013M2A8A 1035822).

\section{References}

[1] Park, J.Y. (2009) Possibility of Fusion Applications of Current Materials R\& D for GEN-IV Nuclear Energy System in KAERI. Korea-Japan Blanket Workshop.

[2] Yoon, J.H., et al. (2014) Characteristics of Domestic Reactor Pressure Vessel Steel after High-Dose Neutron Irradiation. Proceeding of HANARO Symposium.

[3] Lee, Y.M., et al. (2014) A Study on the Irradiated Strength and Stress Evaluation of nuclear Graphite Material. Nuclear Engineering and Design, 269, 193-199.

[4] William, K., et al. (2013) A Review of the Effects of Radiation on Microstructure and Properties of Concrete Used in Nuclear Power Plants. US NRC, NUREG/CR-7171.

[5] Hofman, G.L., et al. (2003) Proceeding of the 2003 RERTR International Meeting, Chicago, 5-10 October 2003.

[6] Jung, H.S., et al. (2014) Microwave Losses of Undoped n-Type Silicon and Undoped 4H-SiC Single Crystals at Cryogenic Temperatures. Electronic Materials Letters, 1-9. 